\title{
The International Journal of Conflicts Management: Uma Análise da Produção Acadêmica à Luz da Bibliometria de 2003 a 2012
}

\section{The International Journal of Conflicts Management: An Analysis of Academic Production in Light of Bibliometrics 2003-2012}

\author{
Rosany Corrêa \\ Doutoranda em Administração na Universidade Nove de Julho \\ Professora Assistente da Universidade Estadual do Piauí \\ BR 343, Km 7,5, Floriópolis, CEP: 64202-260, Parnaíba, PI, Brasil \\ Telefone: (086) 33233250 \\ e-mail: rosanycorrea@hotmail.com

\section{Mauro Silva Ruiz} \\ Doutor em Geografia - Southern Illinois University at Carbondale \\ Endereço profissional: Universidade Nove de Julho, Mestrado em Gestão Ambiental e Sustentabilidade. \\ Av. Dr. Adolpho Pinto, 109, Barra Funda, CEP: 01.156-050 - São Paulo, SP - Brasil \\ Telefone: (11) 36659351 \\ e-mail: maurosilvaruiz@gmail.com

\section{Henrique César Melo Ribeiro} \\ Doutorando em Administração na Universidade Nove de Julho \\ Professor da Faculdade Maurício de Nassau \\ BR 343, Km 7,5, Floriópolis, CEP: 64202-260, Parnaíba, PI, Brasil \\ Telefone: (086) 33234148 \\ e-mail: $\underline{\text { hcmribeiro@gmail.com }}$
}

RESUMO

Este estudo teve como objetivo, mapear o perfil e o crescimento do tema conflitos à luz do periódico The International Journal of Conflicts Management, entre 2003 e 2012. Esta pesquisa apoiou-se em técnicas bibliométricas, utilizou-se de estatística descritiva, nos 180 artigos identificados. Os principais resultados foram: predominância de autoria com dois e três pesquisadores; Posthuma foi o autor mais profícuo. A Universidade do Texas foi a IES que mais publicou artigos e a que teve maior centralidade de grau. E os temas mais evidenciados em 10 anos de publicação foram conflitos e gestão de conflitos.

Palavras-chave: The International Journal of Conflicts Management. Bibliometria. Rede Social.

\section{ABSTRACT}

This study aimed to map the profile and the growing conflict in the light of the theme of the journal The International Journal of Management Conflicts between 2003 and 2012. This research was based on bibliometric

\footnotetext{
1 Artigo recebido em 13.06.2013. Revisado pelos pares em 23.08.2013 (blind review). Ajustado e Aceito para publicação em 16.10.2013. Recomendado para publicação por José Ribamar Marques de Carvalho (Editor Científico). Publicado em 12.12.2013. Organização responsável UACC/CCJS/UFCG.
} 
techniques, we used descriptive statistics, we identified 180 articles. The main results were: predominance authored with two and three researchers; Posthuma was the most prolific author. The University of Texas, was the IES had published more articles and had the greatest degree centrality. And the themes highlighted in 10 years of publication were conflicts and conflict management.

Keywords: The International Journal of Conflicts Management. Bibliometrics. Social Network.

\section{INTRODUÇÃO}

Desde que se sabe da história da civilização se identifica os mais variados tipos de conflitos, os homens ao estabelecerem entre si relações pessoais e ou profissionais concebem situações harmoniosas e conflituosas. Para Barbanti (2010), os conflitos envolvem interesses imiscuídos que vão do individual ao coletivo numa mesma dada situação.

As interações decorrentes de todas as formas de convivência humana delineiam as mais variadas formas sociais, que perpassam desde as afetivas, de dominação, de parcerias, coletivas, internacionais, acordos, cooperativas e judiciais quando os conflitos se exacerbam. O processo social resulta e compreende a interação de inúmeros valores, interesse, ideias e fatores econômicos, políticos, sociológicos e históricos (NOGUEIRA, 2006).

Ao socializar o conhecimento por meio da divulgação científica, na forma digital ou em papel, os periódicos consolidam a produção academica de pesquiadores, de instituições e de nações, formando redes e gerando indicadores de produção. Os indicadores servem para mensurar e avaliar a produção científica, nesse caso a evolução de pesquisas realizadas em periódico internacional. Os indicadores de performance bibliométrica são importantes para avaliar a pesquisa acadêmica e nortear rumos e estratégias de futuros estudos (LEITE FILHO, 2006).

Apesar de varias áreas do conhecimento socializarem em seus periódicos conteúdos relacionados a conflitos, não foi encontrado estudos que tratassem de pesquisa bibliométrica de periódicos internacionais sobre o tema conflitos. Neste contexto, foi definido o periódico The International Journal of Conflicts Management para se realizar este tipo de estudo, por se tratar da revista internacional das mais antigas, que trata sobre a temática conflitos, com publicações sobre o tema desde 1990.

The International Journal of Conflicts Management, possui classificação B1 (CAPES, 2013), publica pesquisa em gestão de conflitos, incluindo artigos originais, teóricos e empíricos (que pode ser tanto quantitativa ou qualitativa) e revisões da literatura críticas ou integrativa, as áreas consideradas relevantes para revista são: Conflito; Gestão de conflitos; Resolução de disputas; Justiça; Instituição 
de justiça; Mediação e arbitragem; Negociação; Estudos para a paz e outros assuntos relacionados.

Ao investigar a temática conflitos através da bibliometria, se consolida um espelho de como a pesquisa cientifica sobre conflitos esta ocorrendo e como as soluções para minimizar ou solucionar as arestas estão sendo implementadas. A pesquisa de gestão de conflitos pode ajudar os gestores, trabalhadores e organizações gerir mais eficazmente os aspectos emocionais do conflito (POSTHUMA, 2012).

Para contribuir com o resgate do conhecimento acumulado no campo de conflitos, o presente estudo, de caráter quantitativo, investigou as publicações internacionais sobre a tematica, delineando as temáticas mais socializadas e as redes das IESs e países, o que confere a relevância ao presente trabalho. Pode-se ressaltar que na literatura nacional e internacional, há poucos estudos bibliométricos dedicados a conflitos.

A questão de pesquisa se define por: Qual o perfil e crescimento do tema conflitos a luz do periódico The International Journal of Conflicts Management? $\mathrm{O}$ objetivo geral consiste em mapear o perfil e o crescimento do tema conflitos a luz do periódico The International Journal of Conflicts Management, entre 2003 e 2012.

O trabalho foi desenvolvido sob a seguinte estrutura, a seção introdutória, a da fundamentação teórica, que aborda os conceitos de conflitos e suas diferentes formas de abordagem e os estudos. Na seção terceira apresenta os procedimentos metodológicos adotados, coleta, análise e tratamento de dados. Já a quarta seção apresenta os resultados da pesquisa, na sequencia é apresentado análises e discussões. A última evidencia as considerações finais, limitações do estudo e recomendações para novos estudos.

\section{FUNDAMENTAÇÃO TEÓRICA}

Esta seção apresenta a evolução do tema conflitos e os estudos desenvolvidos sobre a produção acadêmica da área.

\subsection{Conflitos}

Nas sociedades mais antigas prevalecia à supremacia dos mais fortes sobre os mais fracos, a lei de talhão, duelos e muitas atrocidades para tentar vencer os conflitos. A legalidade veio para normatizar e harmonizar as relações, minimizando e mediando situações conflituosas.

O conflito é o processo que começa quando uma das partes percebe que a outra parte a afetou de forma negativa, ou que a irá afetar de igual forma (THOMAS, 1992), muitas vezes pressupõe queas partes em conflito percebem a mesma 
quantidade deconflito, esquecendo que a outra partepode ter diferentes percepções (MUELLER; CURHAN, 2006).

Os ambientes públicos e privados são profícuos para geração de conflitos, organizações e pessoas se desentendem promovendo a discórdia e o desentendimento. O Estado moderno e a sociedade civil são arenas de lutas nas quais os direitos são constituídos e afirmados pelas classes e grupos sociais (MOTTA, 2008), a existência da normatização legal decorre diretamente da formalidade de mecanismos de controles e de inibição de conflitos existentes, entre entes institucionalizados, indivíduos ou grupos.

Ao longo da história da humanidade, diversos campos do conhecimento, contribuíram para a interpretação das formas violentas de conflitos, como também de outras formas mais sutis de embate entre indivíduos, entre grupos sociais e, afinal, entre Estados (BARBANTI, 2010). O conflito surge nas mais variadas formas: em ambiente familiar, em ambiente de trabalho, entre organizações e entre nações.

A existência de conflito com baixos níveis deixa a organização vulnerável à estagnação, à tomada de decisões empobrecidas, mesmo à falta de eficácia, enquanto que possuir conflito em demasia encaminha a organização diretamente ao caos (HAMPTON; SUMMER; WEBBER, 1973), a compreensão dos conflitos entre vida pessoal e profissional pode auxiliar as organizações no desenho de políticas e no fomento de práticas voltadas ao equilíbrio entre esses dois universos, permitindo maior eficiência e a criação de um ambiente organizacional mais estável e produtivo (OLIVEIRA; CAVAZOTTE; PACIELLO, 2012).

Parayitam e Dooley (2011) sugerem que um nivel moderado de conflito cognitivo, em vez de muito conflito, é sempre desejavel. Necessáriamente o conflito nao significa o fracasso, mas uma readequação de uma situação, que pode ser melhor ou diferente.

A gestão dos conflitos surge quando arenas de contendas se estabelecem e os mecanismos de resoluções são procurados, na tentativa da resolutividade. Os padrõesde gestão de conflitosdentro de uma equipe estão relacionados com variáveis disposicionais no nível individual (DESIVILYA; EIZEN, 2005).

Os mecanismos de resoluções de conflitos existem desde as sociedades grega e romana, a busca da conciliação de forma amigável, sigilosa e célere. Sendo as mais comuns: a arbitragem, a conciliação, a negociação, podendo ocorrer de forma judicial ou extrajudicial.

A arbitragem tem seus primórdios nas sociedades antigas e é considerada uma forma alternativa ao sistema jurídico estatal desde que este foi instituído, na Idade Média (GUERREIRO, 1993), sua celeridade surge da própria especialização, pois o árbitro escolhido pelas partes conflitantes deverá ser conhecedor do tema do conflito 
e das leis aplicáveis para resultar no melhor desfecho para ambas as partes (SOUZA, 2006).

O acesso da Justiça dos Juizados Especiais está pautado na busca permanente da conciliação; da simplicidade, através da informalidade e oralidade; da economia e da celeridade e amplitude dos poderes do Juiz (BATITUCCI; SANTOS; CRUZ, 2008), ao ampliar o acesso à justiça se inova em um mecanismo resolutivo de conflitos entre camadas populares.

Já em 1985, os autores Jackson e Schuler estimulavam a pesquisa bibliometrica ao concluirem em sua meta-analise que enquantohouverambigüidade econflito de papéisnas ciênciasorganizacionaisainda há muito aser aprendido.

Uma meta-análise realizada por Poitras (2012) de 28 trabalhos foi realizada para calcular os tamanhos do efeito das ligações entre os conflitos tarefa, conflito de relacionamento, satisfação e desempenho. Já no estudo de Maney (2004), ficou evidenciado o impacto das reações emocionais na mediação positiva ou negativa nos conflitos. Corrêa; Ribeiro e Ruiz (2012), concluiram eu seu estudo bibliométrico sobre a evolução do tema conflitos socioambientais no Brasil, não atingiu a maturidade na literatura acadêmica nacional.

\section{PROCEDIMENTOS METODOLÓGICOS}

Este estudo se caracteriza como exploratório e descritivo, com abordagem quantitativa e qualitativa. A ideia básica concentra-se em resgatar a memória sobre conflitos através de uma Bibliometria, dos artigos publicados no The International Journal of Conflicts Management no período de 10 anos, o recorte temporal foi definido para oferecer um estudo em estado da arte. Tendo como objetivo geral, mapear o que se produziu no campo de conflitos no periódico The International Journal of Conflicts Management, entre 2003 e 2012.

Para Guedes e Borschiver (2005) a bibliometria é uma ferramenta estatística que permite mapear e gerar diferentes indicadores de tratamento e gestão da informação e do conhecimento, especialmente em sistemas de informação e de comunicação científicos e tecnológicos, e de produtividade, necessários ao planejamento, avaliação e gestão da ciência e da tecnologia, de uma determinada comunidade científica ou país.

As leis bibliométricas, fazem uso da análise matemática e estatística de dados para investigar e quantificar a produção científica sobre determinado assunto, atendendo a princípios do método, como: a citação, a cocitação e a teoria epidêmica (MORAN et al. 2010). Sob essa ótica: a Lei de Bradford que mensura o nível de relevância das revistas sobre determinada área ou tema (CASILLAS, 2005). A Lei de Lotka que descreve a produtividade e as citações de pesquisadores, evidenciando 
aspectos de coautoria e co-citação. E a Lei de Zipf que calcula a quantidade de ocorrências das palavras em vários textos, gerando uma lista de terminações de um determinado tema sendo utilizada para observar qual temática científica é tratada nos estudos (EGGHE, 2005), é importante conhecer as três leis básicas da bibliometria, para o melhor entendimento dos dados (RIBEIRO et al., 2013).

Nos últimos anos houve um notável aumento de estudos bibliométricos, motivados pelo numero crescentes de fontes de informação que oferecem indicadores para evolução de publicações (MARTINEZ, 2009), se trata de um instrumento quantitativo que permite minimizar a subjetividade na analise (GUEDES; BORSCHIVER, 2005).

O estudo também consolidou rede social de instituições e de países, por entender a relevância de rede de produção científica (RIBEIRO et al., 2012), o conhecimento científico é construído pela socialização do mesmo (GUARIDO FILHO et al, 2009).O que torna análise consideravelmente sistêmica e técnica, contribuindo na racionalidade de dados.

\subsection{Procedimentos de coleta dos dados}

A pesquisa utilizou-se de dados disponibilizados do periódico The International Journal of Conflicts Management - ISSN 1044-4068, da qual foram obtidos o total de 180 publicações no período dos últimos 10 anos, entre 2003 e 2012. Os indicadores foram buscados através da análise bibliométrica, sendo eles: (I) evolução dos artigos; (II) características de autoria; (III) autores mais profícuos; (IV) IESs que mais publicaram; (V) rede social das IESs; (VI) países mais produtivos; (VII) rede social dos países; (VIII) frequência das palavras-chave nos títulos; e (IX) temas abordados. A coleta foi realizada na plataforma na revista eletrônica hospedada no site: http://www.emeraldinsight.com/journals.htm?issn=1044-4068.

Os artigos foram catalogados e analisados pro meio dos softwares: os softwares UCINET 6 for Windows, Microsoft Excel 2010. A consolidação dos gráficos também foi realizada por meio desses softwares.

\section{ANÁLISE E DISCUSSÃO DOS RESULTADOS}

Esta seção contempla a análise dos 180 artigos identificados no The International Journal of Conflicts Management, juntamente com uma discussão alargada sobre cada indicador calculado. 
CORRÊA, R.; et al. The International Journal of Conflicts Management: Uma Análise...

\subsection{Evolução dos artigos}

O gráfico 1 evidencia a evolução das publicações por ano no período analisado. Observa-se uma ascensão a partir de 2008 no volume de artigos publicados por ano, sendo que entre os anos de 2008 a 2012, uma produção de mais de 20 papers por ano, o que representa $57,7 \%$ da produção nos últimos cinco anos, sendo que nesses anos se apresentam algumas edições especificas sob a temática de conflitos.

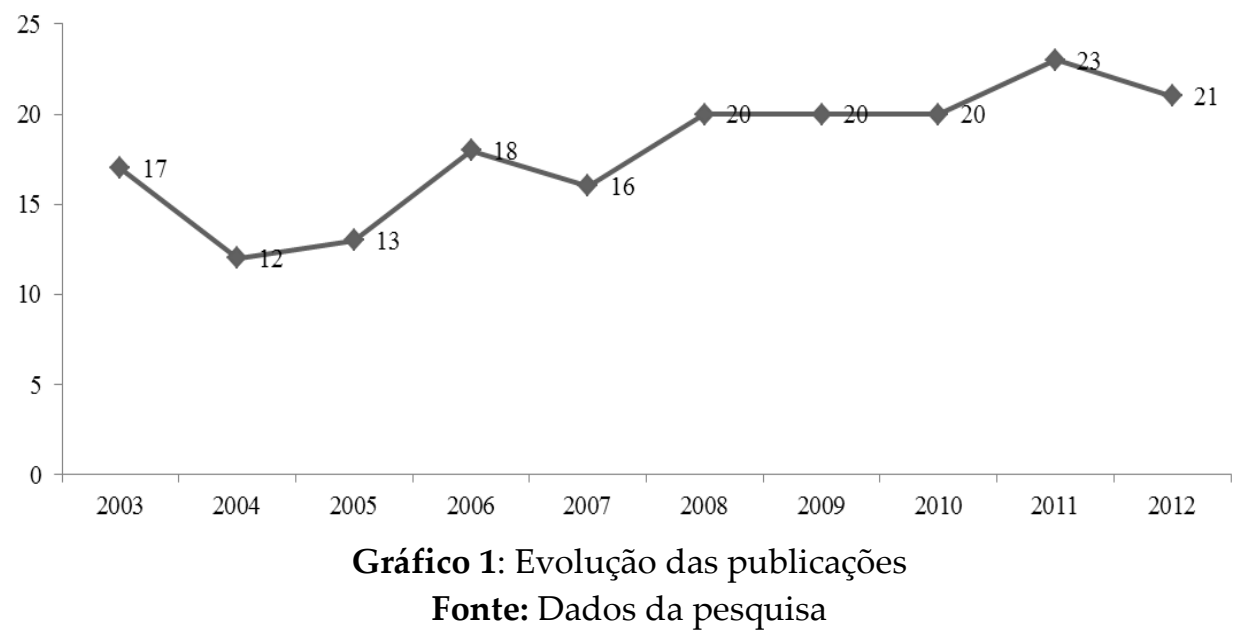

\subsection{Características de autorias}

No gráfico 2 é possível perceber o número de autores por artigos, pode se observar que autoria única e publicações com dois e três autores, representam 85,5\% dos artigos, enquanto cinco ou seis autores representam 6,1\%. Percebe-se uma tendência de autoria individual, sendo que somente em 2004 não houve publicação com um único autor.

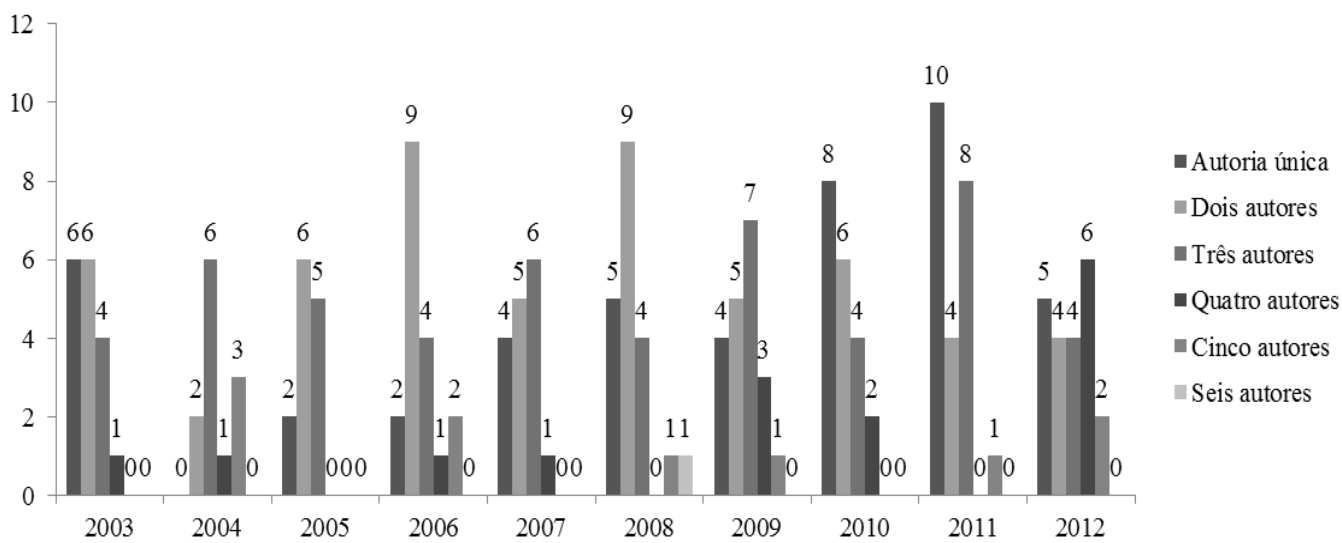

Gráfico 2: Autorias

Fonte: Dados da pesquisa

REUNIR - Revista de Administração, Contabilidade e Sustentabilidade

ISSN: 2237-3667 - Vol.3, no 4, Set./Dez., p. 1-19, 2013. 


\subsection{Autores que mais publicaram}

O gráfico 3 contempla os autores que mais papers publicaram sobre o tema conflitos no periódico, destacando-se os pesquisadores Posthuma (Universityof Texas), com seis papers, Jehn (Leiden University) com 5 artigos, Tjosvold (Lingnan University) e Poitras (HEC Montreal), com 4 publicações, Kidder (University of Hardford), Miles (Georgia State University) e Parayitam (University of Massachusetts), com 3 publicações. Sendo que 334 autores contribuíram com a publicação de 1 artigo. Confirmando a Lei de Lotka que afirma que poucos pesquisadores publicam muito e muitos autores publicam muito, evidenciando a relevância dos autores mais profícuos.



Gráfico 3: Autores mais produtivos

Fonte: Dados da pesquisa

\subsection{Instituições que mais publicaram}

O gráfico 4 apresenta as 13 instituições que publicaram mais de 2 artigos no periódico The International Journal of Conflicts Management durante os últimos 10 anos. A University of Texas, teve 11 artigos publicados, seguida da Leiden University com 6 artigos e a Michigan State University e a University of Groingen tiveram 5 publicações, tendo um grupos de sete instituições superiores, sendo: California State University, City University of Hong Kong, Lingnan University, Northwestern University, Rudgers University e Vanderbit University tiveram 4 papers publicados.

Evidencia-se que dentre essas instituições, 6 delas são dos Estados Unidos da América (EUA), duas são da China, uma da Holanda, uma da Noruega e uma do Canadá. 
CORRÊA, R.; et al. The International Journal of Conflicts Management: Uma Análise...

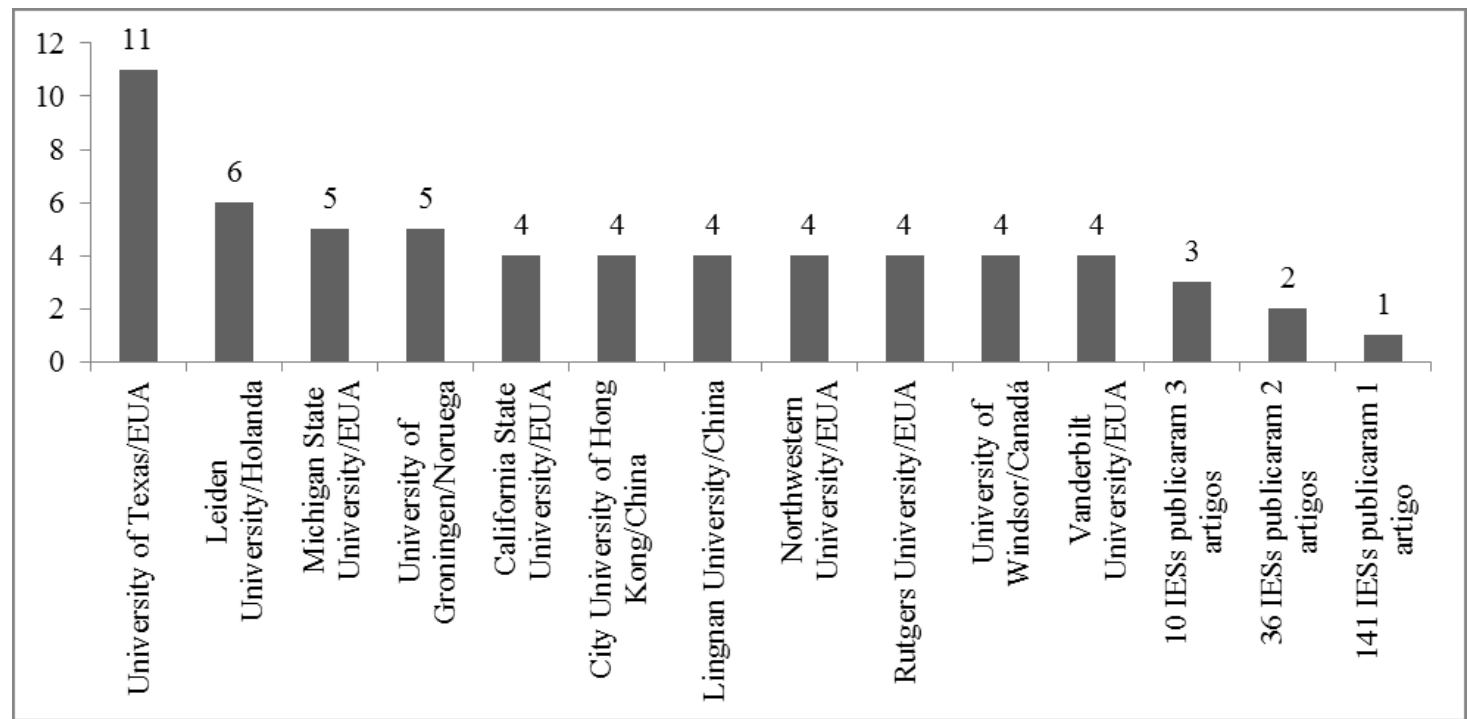

Gráfico 4: Instituições de Ensino Superior mais produtivas

Fonte: Dados da pesquisa

\subsection{Rede social das IESs}

A Figura 1 apresenta as cinco principais redes sociais das instituições, ressaltase que destas 3 se localizam nos Estados Unidos da América (EUA).

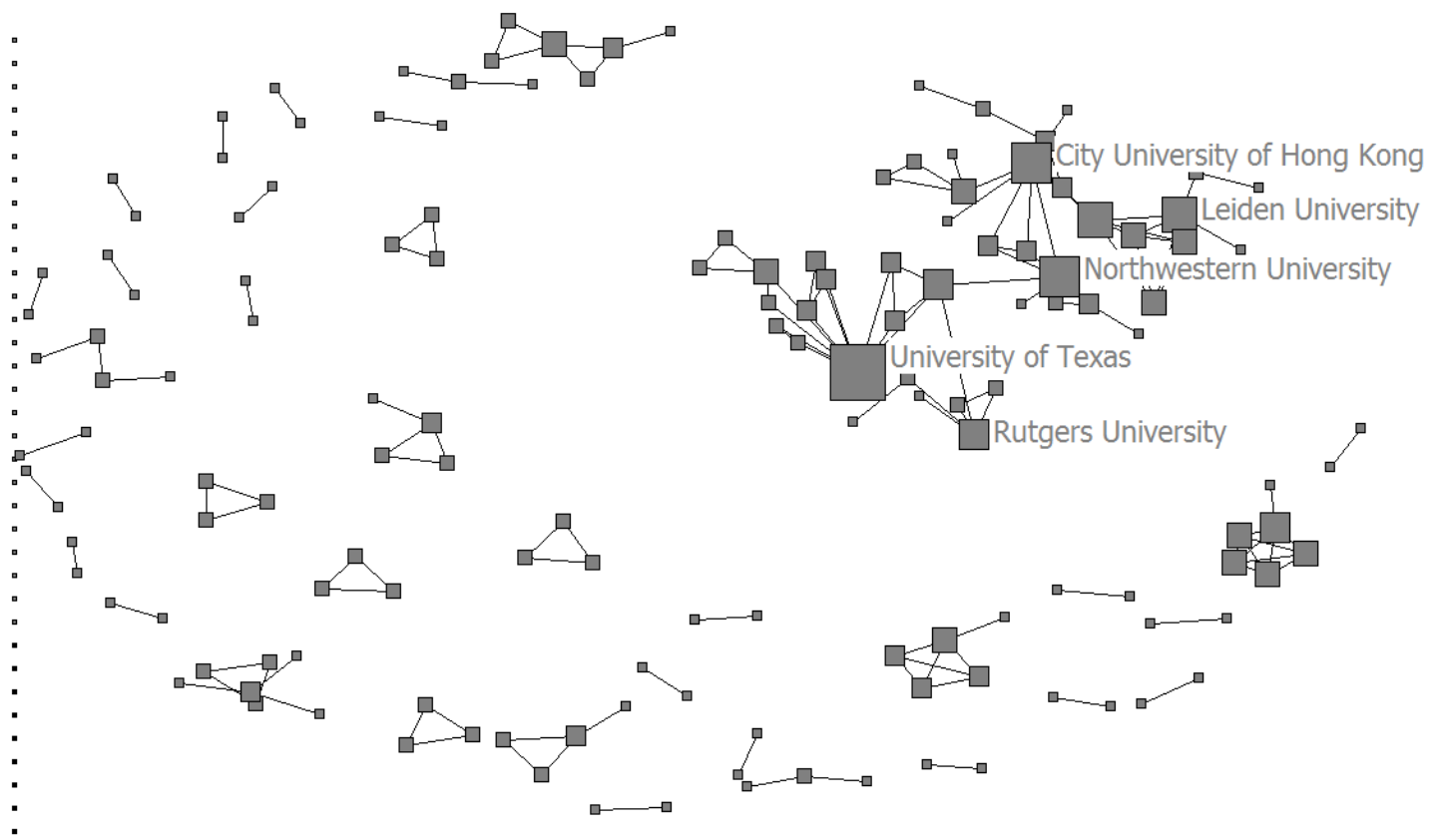

Figura 5: Rede de instituições

Fonte: Dados da pesquisa

REUNIR - Revista de Administração, Contabilidade e Sustentabilidade

ISSN: 2237-3667 - Vol.3, no 4, Set./Dez., p. 1-19, 2013. 
CORRÊA, R.; et al. The International Journal of Conflicts Management: Uma Análise...

A principal rede esta ligada a University of Texas (EUA), com 12 nós, seguida da City University of Hong Kong (China) e da Northwesten University (EUA), ambas com 7 nós. A Leiden University (Holanda) possui 6 nós e a Rutgers University (EUA) com 5 nós. Esse resultado confirma que a University of Texas tem vinculado a ela o maior número de artigos publicados e o autor mais profícuo.

Observa-se uma integração para publicação entre as instiuições, o que é benefico uma vez que a temática conflitos de gestão, de apresenta de diferentes formas com os países interligados, e as investigações contribuem para socializar as formas que se estabelecem os conflitos e suas resoluções.

\subsection{Países mais produtivos}

Os autores vinculam suas produções cientificas a vinte e sete países (Gráfico 5), sendo que dentre eles as cinco nações que mais publicaram foram: Estados Unidos da América (EUA) 100 artigos; China 21 publicações, Canadá 15, Holanda 12 artigos e Austrália com 10 publicações. Conjuntamente representam 87,7 \% dos manuscritos publicados na revista The International Journal of Conflicts Management. O Brasil aparece com quatro publicações juntamente com Japão, Inglaterra e Turquia.

A investigação sobre conflitos deve ser mais internacional porque o negócio está cada vez mais internacional e há um número crescente de influências internacionais em muitas áreas da vida cotidiana (POSTHUMA, 2005) e conflitos cada vez mais devem ocorrer em virtude dos negócios ocorrerem a nível global.

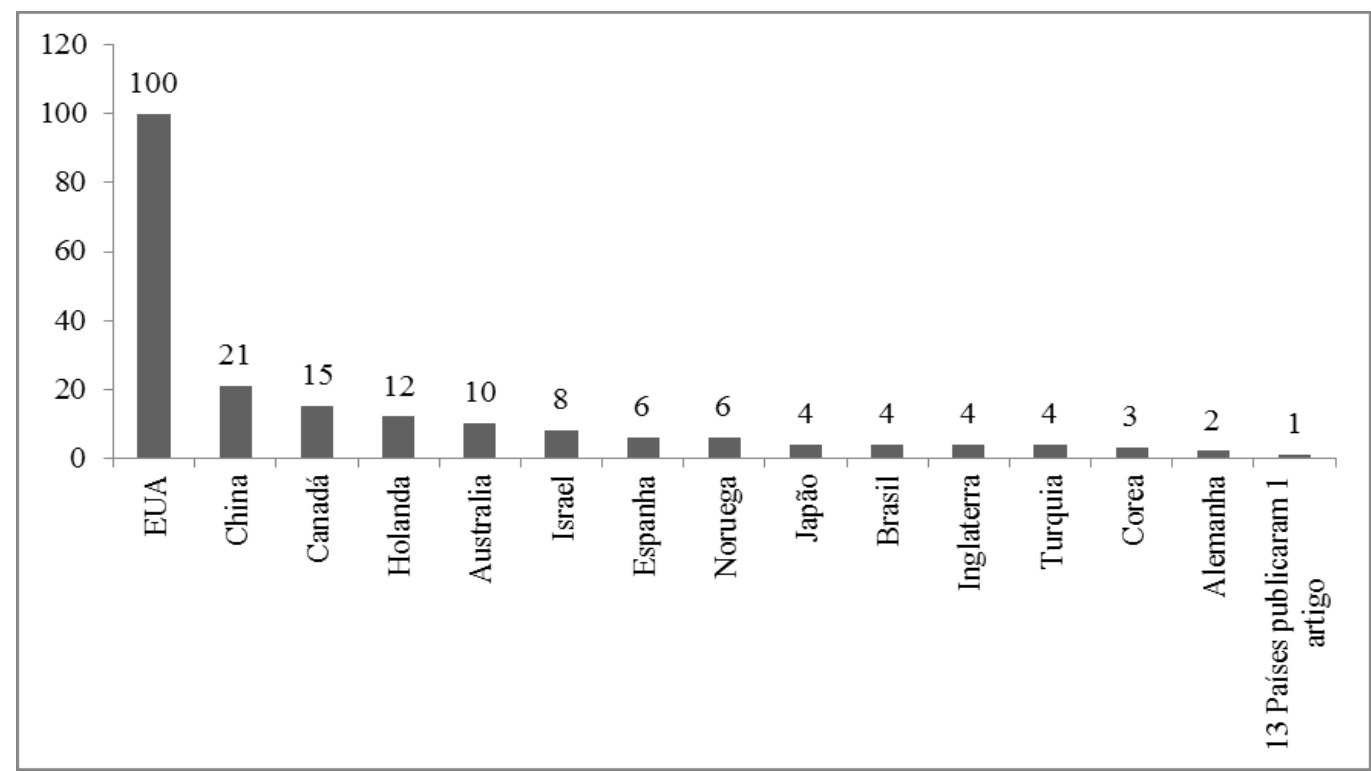

Gráfico 5: Países mais produtivos

Fonte: Dados da pesquisa

REUNIR - Revista de Administração, Contabilidade e Sustentabilidade

ISSN: 2237-3667 - Vol.3, no 4, Set./Dez., p. 1-19, 2013. 
CORRÊA, R.; et al. The International Journal of Conflicts Management: Uma Análise...

\subsection{Rede social entre países}

A rede social entre os países (Figura 2) se estabelecem a partir da integração de autores (nacionalidade) e de instituições que eles representam, evidenciando as relações que se estabelecem a partir das autorias e coautorias que produziram o conhecimento cientifico.

A Figura 2 apresenta a rede estabelecida entre países no período dos ultimos 10 anos no períodico objeto de estudo, e que vinculou198 IESs a 431 autores, evidenciando a centralidade dos Estados Unidos da América (EUA), seguido da China e da Holanda na rede de produção científica entre os 27 países que compuseram a referida rede, o que se confirma na rede de instituições.

Tal fato pode ser decorrente de existir um maior numero de pesquisadores publicando das mesmas instituições o que consolita pesquisadore e áreas de pesquisa nas IESs. As culturas, ideologias, idioma e outras qualidades proprias de cada país, impôem uma integração maior nas relações de pesquia entre ele, uma vez que diferenças internas ou externas nas nações podem mitigar os conflitos e a gestão dos conflitos.

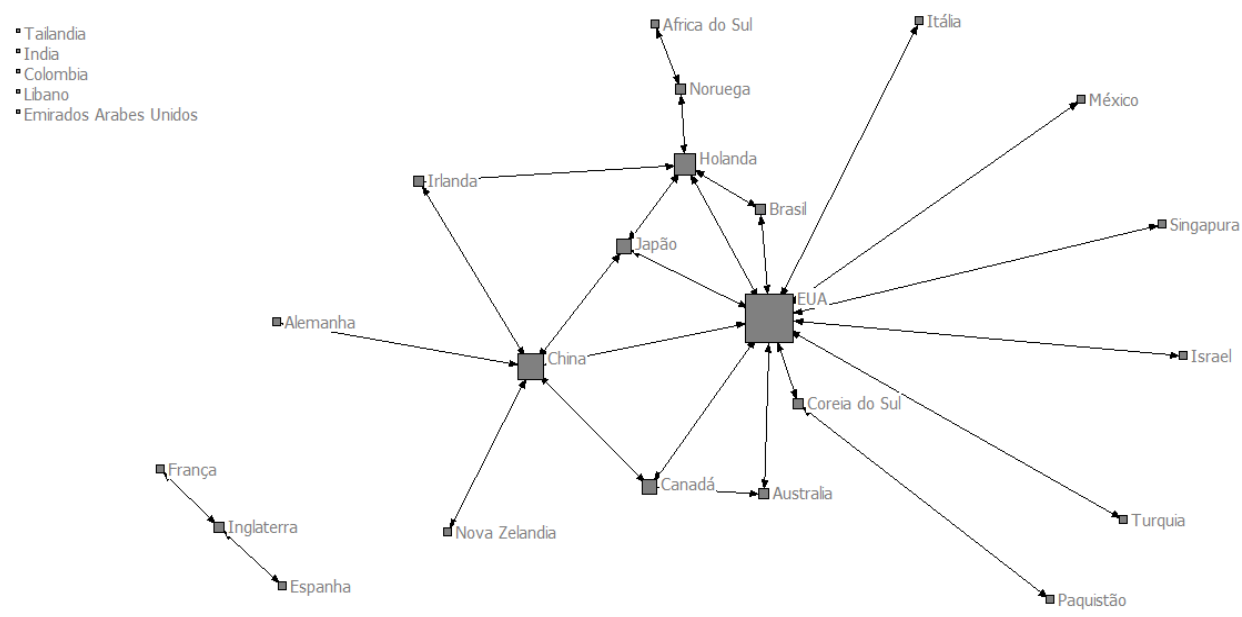

Figura 2: Rede entre países

Fonte: Dados da pesquisa

Alguns estudos sugerem alternativas para redimir conflitos: redefinir a ideologia, transformá-la em uma poderosa ferramenta conceitual para ser usada na pesquisa acadêmica, uma vez que precisamente a ausência de categorias abrangentes de análise impede estudiosos de fornecerem um quadro completo da situação política e cultural dimensões dos conflitos armados contemporâneos (UGARRIZA, 
2009),são necessárias mais pesquisasquecomparem especificamentea influência das emoçõessobrea gestão de conflitosem váriasculturas (POSTHUMA, 2012).

\subsection{Frequência de palavras-chave}

A Figura 3 contempla as palavras-chave mais repetidas dos 180 papers publicados no periódico The International Journal of Conflicts Management.

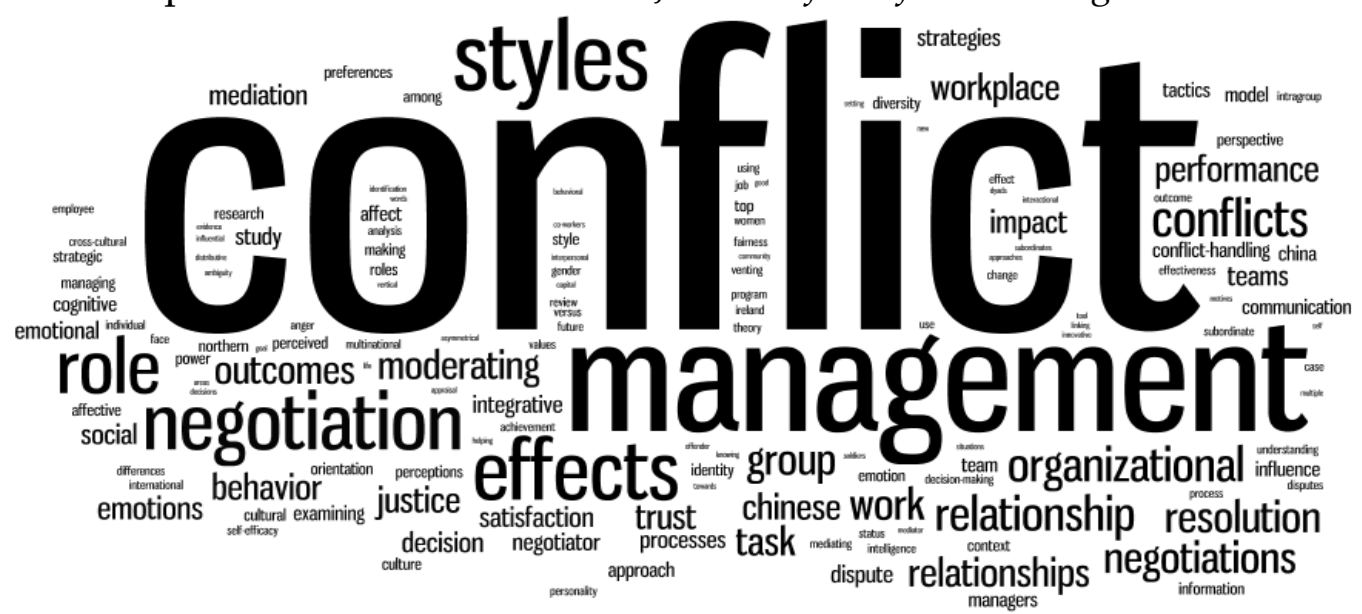

Figura 3: Palavras-chave

Fonte: Dados da pesquisa

Segundo a Lei de Zipf a frequência de ocorrência de palavras evidencia o desenvolvimento de conteúdos mais abordado nos artigos científicos, sendo que nesse estudo a palavra conflito foi a mais citada em $47,78 \%$ dos artigos, seguido de gestão de conflitos, essa com 13,89\%. Caracterizando que 61,67\% dos artigos publicados na revista tem nos seus títulos o indicativo da abordagem conceitual, confirmando a citada Lei. Outras temáticas estudadas foram: estilos, negociação, efeitos, organizações e desempenho. Tendo uma dispersão de palavras como: justiça, resultados, local de trabalho, tarefa, mediação, comportamento e afeto, dentre outros, configurando a amplitude que a temática conflito abrange. Observe na Tabela 1, que apresenta os temas e subtemas.

\subsection{Temas abordados}

Os temas sugeridos pelo periódico são: conflitos; gestão de conflitos; resoluçãode disputas; justiça; instituição de justiça; mediação e arbitragem; negociação; estudos para a paz e outros assuntos relacionados, foram integrados os subtemas desenvolvidos nos 180 artigos objeto de estudo, conforme demonstra a tabela 1. 
Tabela 1: Temas e subtemas

\begin{tabular}{|c|c|c|}
\hline Temas/Subtemas & Artigos & $\%$ \\
\hline Conflitos & 86 & $47,78 \%$ \\
\hline Organizacionais & 27 & $15,00 \%$ \\
\hline Comportamentais & 23 & $12,78 \%$ \\
\hline Interno no País & 21 & $11,67 \%$ \\
\hline Teorias de conflitos & 11 & $6,11 \%$ \\
\hline De interesses & 4 & $2,22 \%$ \\
\hline Gestão de Conflitos & 25 & $13,89 \%$ \\
\hline Entre nações & 11 & $6,11 \%$ \\
\hline Em cooperativas & 2 & $1,11 \%$ \\
\hline Simulados & 4 & $2,22 \%$ \\
\hline E a comunicação & 3 & $1,67 \%$ \\
\hline Intragrupos & 5 & $2,78 \%$ \\
\hline Resolução de disputas & 9 & $5,00 \%$ \\
\hline Custos de transação & 4 & $2,22 \%$ \\
\hline Percepção dos resultados & 5 & $2,78 \%$ \\
\hline Justiça & 5 & $2,78 \%$ \\
\hline Equidade & 5 & $2,78 \%$ \\
\hline Instituição de justiça & 7 & $3,89 \%$ \\
\hline Restaurativa & 3 & $1,67 \%$ \\
\hline Processual & 4 & $2,22 \%$ \\
\hline Mediação e arbitragem & 7 & $3,89 \%$ \\
\hline Diferenças na arbitragem & 3 & $1,67 \%$ \\
\hline Em organização & 2 & $1,11 \%$ \\
\hline Entre pessoas & 2 & $1,11 \%$ \\
\hline Negociação & 21 & $11,67 \%$ \\
\hline Cooperação & 5 & $2,78 \%$ \\
\hline Influencia da emoção & 5 & $2,78 \%$ \\
\hline Dimensões & 5 & $2,78 \%$ \\
\hline Tipos & 6 & $3,33 \%$ \\
\hline Estudos para paz & 0 & $0,00 \%$ \\
\hline Outros & 20 & $11,11 \%$ \\
\hline Ensino e pesquisa & 3 & $1,67 \%$ \\
\hline Tomada de decisão & 4 & $2,22 \%$ \\
\hline Motivação psicológica & 7 & $3,89 \%$ \\
\hline Valores culturais & 6 & $3,33 \%$ \\
\hline Total & 180 & $100,00 \%$ \\
\hline
\end{tabular}

Fonte: Dados da pesquisa

REUNIR - Revista de Administração, Contabilidade e Sustentabilidade

ISSN: 2237-3667 - Vol.3, no 4, Set./Dez., p. 1-19, 2013. 
A Tabela 1 identifica os temas e os subtemas, sendo que conflitos, gestão de conflitos e resolução de conflitos são os temas e mais evidenciados, consubstanciados pelos subtemas desenvolvidos nos artigos. Desta forma se configura a abrangência que tem a gestão de conflitos, pois envolve muitos aspectos, que vão desde o conceito, perpassando pela gestão, por mecanismos de resolução de conflitos e valores pessoais.

Estudos confirmam que o conflito pessoal tem seu efeito sobre conflitos interpessoais, a confiança modera o comportamento, contribuindo para a tomada de decisão estratégica dos lideres (PARAYITAM; OLSON;BAO, 2010).

Valores, motivação psicológica, influência de percepção, influência de emoção, ainda são pouco estudadas, o que é confirmado no estudoque observoua ligação entreemoçõese conflitos, tendo esses assuntos recebido poucaatenção, tantona literatura, quanto na produção academica (NAIR, 2008).

Os mecanismos de resolução de conflitos como mediação, arbitragem e negociação, se apresentam de forma tímida, configurando assunto que não é recente e que foi pouco evidenciado. Apesar de a arbitragem ser pouco conhecida e pouco reconhecida no Brasil como sendo um processo passível de utilização para solucionar conflitos comerciais, seu crescente uso e maior divulgação contribuirão para uma mudança na forma de se administrar conflitos surgidos das crescentes relações internacionais (SOUZA, 2006). Sendo que o tema estudos da paz, nao foi indentificado nenhum estudo.

\section{CONSIDERAÇÕES FINAIS}

Este trabalho mapeou através de um estudo bibliométrico e de redes a produção cientifica do periódico The International Journal of Conflicts Management, através de 180 artigos publicados nos últimos 10 anos.

Esta pesquisa mostrou que os temas: conflitos e gestão de conflitos, resoluçãode disputas; justiça; instituição de justiça; mediaçãoe arbitragem; negociação; estudos para a paz e outros assuntos relacionados receberam contribuição de 198 instituições e envolveram 431 autores de 27 nacionalidades, evidenciando uma integração de parcerias entre autores e instituições, o que contribui para busca conjunta através de estudos que possam orientar ou evidenciar como esta sendo tratado a temática conflitos na literatura acadêmica internacional.

A pesquisade gestão de conflitospode ajudar os gestores, trabalhadores e organizaçõesgerir mais eficazmenteos aspectos emocionais doconflito (POSTHUMA, 2012). 
Verificou-se neste estudo que a partir de 2008 um acréscimo no volume de artigos publicados no periódico. Os EUA se apresenta como o país com maior número de publicações (100 artigos) e mais central na rede tanto de instituições como de países, dentre os 27 que publicaram no período, confirmando uma grande produção científica.

Os autores que mais produziram no período foram os pesquisadores Posthuma (6 artigos), Jehn (5 artigos), Tjosvolde Poitras (4 artigos), Kidder, Miles e Parayitam (3 artigos), tal resultado se confirma com o vinculo de Posthuma a instituição mais prolifera e com centralidade de grau.

As instituições mais produtivas foram, University of Texas, Leiden University, Lingnan University, HEC Montreal, University of Hardford, Georgia State University e University of Massachusetts, sendo também a University of Texas a mais central na rede de IES.

Notou-se que os artigos com uma, duas ou três autorias são os mais vistos, representam conjuntamente $85,5 \%$ dos artigos, sendo que tende para autorias de duas e três autorias com 108 artigos, já com seis autores teve somente um artigo publicado no período.

Os resultados sugerem que a produção cientifica no periódico é abrangente e envolve um número considerável de pesquisadores, relacionando-os em rede de cooperação para produção acadêmica. Concluiu-se neste estudo, de maneira geral, um perfil para produção de artigos que tratam de conflitos sob os aspectos organizacionais, comportamentais, internos e externos de nações, apresentam poucos estudos sobre a emoção e valores que envolvem situações de conflito, não apresentando nenhum estudo sobre conflitos socioambientais, o que significa uma lacuna na produção do periódico.

Este estudo apresenta como limitação a pesquisa realizada em um único periódico, o que proporcionaria uma comparação entre periódicos. $\mathrm{O}$ estudoevidencia a necessidade demais pesquisassobre formas de mediação de conflitos, de resultados desses acordos e das emoçõesem situações de conflito.

Embora esteestudo representediversos países é necessária mais investigaçãoque, especificamente,compare e evidenciea influência dagestão de conflitosemvárias culturas. Sugere-se também, comparar estudos entre periódicos, com intuito de investigar a abrangência de conflitos em todas as áreas que ocorrem.

\section{REFERÊNCIAS}

BARBANTI, O. J. Conflitos socioambientais: teorias e práticas, 2010. Disponível em:< http://www.uni-tuebingen.de/egwinfo/susam/download/barbanti.pdf $>$ Acesso em: 09 abr. 2013. 
CORRÊA, R.; et al. The International Journal of Conflicts Management: Uma Análise...

BATITUCCI, E. G.; SANTOS, A.; CRUZ, M.V. G. Novas perspectivas do judiciário na mediação de conflitos: o caso do juizado especial criminal. In: ASSOCIAÇÃO NACIONAL DE PÓS-GRADUAÇÃO DE PESQUISA EM ADMINISTRAÇÃO. ANPAD. Anais Eletrônicos... Porto Alegre: ANPAD, 2006. Disponível em: $<$ http: \\www.anpad.org.br.> Acesso em 25 abr. 2013.

CAPES - Coordenação de Aperfeiçoamento de Pessoal de Nível Superior. Webqualis. Disponível em: <http://www.qualis.capes.gov.br>. Acesso em: 28 abr.2013.

CASILLAS, J. C. Current paradigms in the international management field: an Author co-citation analysis. International Business Review, v. 14, p. 619-639, 2005.

CORRÊA R.; RIBEIRO H. C. M.; RUIZ M.S. Perfil e evolução do tema conflitos socioambientais: uma bibliometria dos últimos vinte anos dos periódicos da área de administração no Brasil. Revista de Administração, Contabilidade e Sustentabilidade, v.2, n. 4, p. 58-75, 2012.

DESIVILYA, H.S. EIZEN, D. Conflict management in work teams: the role of social self-efficacy and group identification. The Internacional Journal of Conflict Management, v. 16, n.1, p. 102-127, 2005.

EGGHE, L. Zipfi an and lotkai an continuous concentration theory. Journal of the American Society for Information Science and Technology, v. 56, n. 9, p. 935-945, 2005

GUEDES, V.L.S.; BORSCHIVER, S. Bibliometria uma ferramenta estatística para a gestão da informação e do conhecimento em sistemas de informação, de comunicação e de avaliação científica e tecnológica. In: ENCONTRO NACIONAL DA CIÊNCIA E DA INFORMAÇÃO. Anais Eletrônicos... Salvador, 2005. p.1-18

GUERREIRO, J. A. T. Fundamentos da arbitragem do comércio internacional. São Paulo: Saraiva, 1993.

HAMPTON, D. R.; SUMMER, C. E.; WEBBER, R. A. Organizational behavior and human performance. Glenview, IL: Scott Foreman, 1982.

REUNIR - Revista de Administração, Contabilidade e Sustentabilidade

ISSN: 2237-3667 - Vol.3, no 4, Set./Dez., p. 1-19, 2013. 
CORRÊA, R.; et al. The International Journal of Conflicts Management: Uma Análise...

JACKSON S. E.; SCHULER R. S. A meta-analysis and conceptual critique of research on role ambiguity and role conflict in work settings. Organizational Behavior and Human Decision Processes, v. 36, n. 1, p. 16-78, 1985.

LEITE FILHO, Geraldo A. Padrões de produtividade de autores em periódicos de congressos na área de contabilidade no Brasil: um estudo bibliométrico. In: Congresso USP Controladoria e Contabilidade. Anais Eletrônicos... São Paulo: Congresso USP de Controladoria e Contabilidade, 2006. Disponível em: $<$ http://www.congressousp.fipecafi.org/artigos62006/an_resumo.asp?cod_trabalho=8 4>Acesso em: 19 abr. 2013.

LITTLE P. E. A etnografia dos conflitos socioambientais: bases metodológicas e empíricas. Horizontes Antropológicos, v. 12, n. 25, p. 85-103, 2006.

MANEY, G. M. Variations in the causes of ethnonationalist violence: northern Ireland. The International Journal of Conflict Management, v. 16, n.1, p.70-96. 2005.

MARTINEZ, L. J. Bibliometria y Academia. Anuário Think EPI. EPI SCP, p, 23-26, 2009,

MORAN, M. R.; SOUZA, F. F. A.; BOAVENTURA, J. M. G.; MARINHO, B. L.; FISCHAMANN, A. A. Alianças Estratégicas: uma análise bibliométrica da produção científica entre 1989 e 2008. Revista de Ciências de Administração, v.12, n. 27, p. 4262, 2010.

MOTTA, L. T.O conceito de estado e de sociedade civil na perspectiva relacional: conflitos e relações de poder nas arenas públicas. In: ENCONTRO DE ADMINISTRAÇÃO PUBLICA E GOVERNANÇA. ANPAD. Anais...Salvador-BA, 12 a 14 ago. 2008.

MUELLER J. S.; CURHAN J. R.. Emotional intelligence and counterpart mood induction in a negotiation. The International Journal of Conflict Management, v. 17, n.2, p. 110-128, 2006.

NAIR, N.Toward sunder standing the role of emotions in conflict: a review and future directions. The International Journal of Conflict Management v. 19, n.4, p. 359-381, 2009.

REUNIR - Revista de Administração, Contabilidade e Sustentabilidade

ISSN: 2237-3667 - Vol.3, no 4, Set./Dez., p. 1-19, 2013. 
NOGUEIRA, E. Conflitos No Contexto Institucional. In: ASSOCIAÇÃO NACIONAL DE PÓS-GRADUAÇÃO DE PESQUISA EM ADMINISTRAÇÃO. IV ENEO. Anais Eletrônicos... Porto Alegre: ANPAD, 2006. Disponível em: $<$ http://www.anpad.org.br.> Acesso em 25 abr. 2013.

OLIVEIRA L. B.; CAVAZOTTE, F. S. N.; PACIELLO R. R., Universos em Desalinho: Antecedentes e Consequências dos Conflitos entre Família eTrabalho. In: ASSOCIAÇÃO NACIONAL DE PÓS-GRADUAÇÃO DE PESQUISA EM ADMINISTRAÇÃO. ANPAD, Anais...Rio de Janeiro-RJ, 2012. Disponível em: $<$ http:\\www.anpad.org.br.> Acesso em 25 abr. 2013.

PARAYITAM,S.; OLSON, B. J.; BAO Y. Task conflict, relationship conflict and agreement-seeking behavior in Chinese top management teams. The International Journal of Conflict Management, v. 21, n. 1, p.94-116, 2010.

PARAYITAM, S.; DOOLEY, R.. Is too much cognitive conflict in strategic decisionmaking teams too bad? The International Journal of Conflict Management, v. 22, n. 4, p. 342-357, 2011.

POITRAS, J. Mediation: depolarizing responsibilities to facilitatere conciliation. The International Conflict Management Research. v.21, n.1, p. 4-19, 2010.

POSTHUMA, R. A. The Need For More Influential International Conflict Management Research. The International Conflict Management Research,v.16, n.3, p. 212-217, 2005.

POSTHUMA, R. A. Conflict management andemotions. The International Journal of Conflict Management, v. 23, n. 1, p.4-5, 2012.

RIBEIRO, H.C.M.; COSTA, B. K.; FERREIRA, M. P.; CARMONA ,V.C.. Mapeando os Temas Estratégia e Governança Corporativa: Uma análise dos últimos 23 anos de estudo nos periódicos internacionais da área de administração. In: VI ENCONTRO DE ESTUDOS EM ESTRATÉGIA, Anais... Bento Gonçalves-RS, 2013.

RIBEIRO H.C.M.; COSTA B. K.; FERREIRA M. P ; SERRA B. P. C. Produção científica sobre os temas governança corporativa e stakeholdes em periódicos internacionais. In: ASSOCIAÇÃO NACIONAL DE PÓS-GRADUAÇÃO DE PESQUISA EM ADMINISTRAÇÃO. ANPAD, Anais... Rio de Janeiro, RJ, 22 a 26 set 2012. 
CORRÊA, R.; et al. The International Journal of Conflicts Management: Uma Análise...

SOUZA, D. N. Eficácia da Arbitragem Comercial Internacional na Resolução de Conflitos no Comércio Exterior Brasileiro. In: ASSOCIAÇÃO NACIONAL DE PÓSGRADUAÇÃO DE PESQUISA EM ADMINISTRAÇÃO. ANPAD, Anais...Salvador BA, 23 a 27 set 2006.

THOMAS Kenneth W. Conflict and conflict management: Reflections and update. Journal of Organizational Behavior, p. 265-274, 1992.

THOMAS, K. W. Conflict and negotiation processes in organizations. In M. D. DUNNETTE;HOUGH (Eds.). Handbookof Industrial and Organizational Psychology, v. 3, n. e, p. 651-717, 1992.

UGARIZZA, J. E. Ideologies and conflict in the post-Cold War. The International Conflict Management Research, v.20, n.1, p. 82-104, 2009. 